\title{
TENSÕES ENTRE A DIPLOMACIA BRASILEIRA E A LATINO- AMERICANA NA LIGA DAS NAÇÕES NA DÉCADA DE 1920.
}

\author{
Filipe Queiroz de Campos*
}

Resumo: Nesse artigo, analisaremos as tensões diplomáticas entre o Brasil e os países latino-americanos na Liga das Nações, e como essas tensões ajudam a explicar a decisão brasileira de transformar sua candidatura a membro permanente do Conselho dessa organização internacional em uma verdadeira política externa do governo de Arthur Bernardes. Demonstraremos, portanto, importantes novidades documentais e analíticas que contribuem para a compreensão da história da diplomacia brasileira na década de 1920.

Palavras-chave: Liga das Nações, diplomacia latino-americana, Arthur Bernardes.

\section{TENSIONS BETWEEN BRAZILIAN AND LATIN AMERICAN DIPLOMACY IN THE LEAGUE OF NATIONS IN THE DECADE OF 1920.}

\begin{abstract}
In this article, we shall analyse diplomatic tensions between Brazil and Latin America countries in the League of Nations and how such tensions help us to explain the Brazilian decision to transform our application to be member from the Counsil of this organization into a really foreign policy of Arthur Bernardes' government. We shall
\end{abstract}

\footnotetext{
* Mestrando em História na Linha Poder, Mercado e Trabalho pela Universidade Federal de Juiz de Fora. e-mail: filipeqc@hotmail.com. 


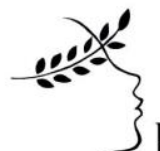

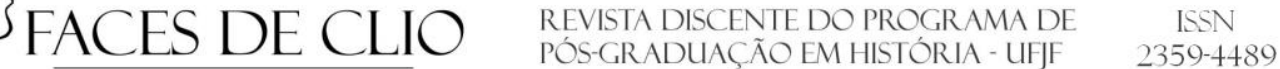

demonstrate henceforth paramount documents and analysis which may contribute to the History of Brazilian Diplomacy in the decade of 1920.

Key words: League of Nations, Latin American diplomacy, Arthur Bernardes.

\section{Introdução}

Com o fim da Primeira Guerra Mundial, há uma profunda busca pela reestruturação da diplomacia e muitos países passam a se integrar no debate internacional sobre as formas de evitar-se algo semelhante à guerra que arrasou por volta de 9 milhões de vidas humanas. Esse novo debate ocorreu na Sociedade das Nações ou Liga das Nações, organização criada especialmente para repensar a política internacional. Nesse mesmo momento, no Brasil, durante o que ficou conhecido como segunda fase da Primeira República, ou seja, entre a Primeira Guerra Mundial e o governo de 1930, instalaram-se os mandatos de Epitácio Pessoa e de Artur Bernardes, cobrindo os anos de 1919 a 1926. Esses dois governos buscaram ativamente participar dessa remodelação profunda das relações internacionais, inserindo o Brasil de forma inédita nos mais altos debates sobre diplomacia.

O governo de Artur Bernardes elaborou um caro e ousado plano diplomático para alcançar um assento permanente na Liga, sendo o Brasil o único país a se instalar nas reuniões dessa organização em Genebra com o status de embaixada, sendo o membro temporário mais votado e reeleito até antes de sua saída. O projeto brasileiro na Liga no fim do governo Epitácio e durante o governo Bernardes foi de tornar-se membro permanente do Conselho Executivo da Liga, órgão de decisão para todos os assuntos mais relevantes da política internacional da época. O Brasil usou de todos os artifícios para alcançar esse cargo, chegando até mesmo vetar a entrada da Alemanha na Liga caso esse país entrasse como permanente, e o Brasil não. O veto foi uma ação extremada que nem os próprios diplomatas brasileiros aprovaram, sendo determinada apenas pela vontade do presidente e do Ministro das Relações Exteriores.

\begin{tabular}{l|lll|l} 
VOL. 4 & N.7 & JAN/JUN. 2018
\end{tabular} 
A historiografia apresenta diversos motivos ainda pouco explorados para a construção dessa insistente política externa brasileira. Neste artigo exploraremos as tensões entre a diplomacia brasileira e a latino-americana no sentido de esclarecermos como essa tensão contribuiu para pressionar a busca brasileira por um lugar permanente no Conselho da Sociedade das Nações.

A Liga das Nações foi, até o momento de sua criação, a mais elaborada tentativa de organizar pacificamente as relações internacionais. Como assinala o historiador Eric Hobsbawm $^{1}$, se a Primeira Guerra Mundial demarca o colapso de conceitos políticos próprios do século XIX, a Liga das Nações foi a tentativa de desenvolver uma nova ordem internacional para o século XX. A Liga representou a primeira organização internacional a oficialmente substituir as dinâmicas de poder tradicionais da geopolítica, fundadas desde o Congresso de Viena, em 1815. Nesse Congresso, as potências monarquistas organizaram um equilíbrio de forças baseado nos princípios do Antigo Regime; esse equilíbrio ficou conhecido como Concerto Europeu. Ao final da Grande Guerra, porém, o "equilíbrio de poder" passou a ser identificado como parte das políticas que levaram à Guerra. A diplomacia secreta contribuiu com uma intrincada rede de tratados bélicos que foram acionados com o início da guerra europeia, tornando-a uma guerra mundial. Após a Guerra, o presidente dos EUA, Woodrow Wilson, apresentou à Conferência de Paz de Paris, em 1919, o projeto de uma nova ordem mundial, guiada pela ideia de transparência, envolvimento da opinião pública na política e igualdade de soberania entre as nações. Essa nova ordem seria materializada e garantida por meio da Liga.

Com a Liga das Nações, o "equilíbrio de poder" seria substituído por uma "comunidade de poder compartilhado" 2 ". A diplomacia secreta foi considerada um dos elementos que mais contribuíra para a generalização da guerra de $1914^{3}$. A partir da

\footnotetext{
${ }^{1}$ HOBSBAWN, Eric. A era dos extremos: o breve século XX. 1941-1991. São Paulo: Companhia das Letras, 1995. p. 90.

${ }^{2}$ SARAIVA, José Flávio Sombra. História das Relações Internacionais Contemporâneas . São Paulo: Saraiva, 2006. p. 45.

${ }^{3}$ SARAIVA, José Flávio Sombra. História das Relações Internacionais Contemporâneas . São Paulo: Saraiva, 2006. p. 245.
} 
década de 1920, portanto, de acordo com Mônica Herz ${ }^{4}$, o conceito de multilateralismo foi um dos elementos políticos mais representativos da nova realidade geopolítica engendrada pela Conferência de Paris, favorecendo uma ordem baseada na publicidade dos atos internacionais.

A Liga estava dividida em dois órgãos: a Assembleia, na qual todos os países buscariam resolver questões gerais pouco conectadas com conflitos internacionais, e o Conselho, composto apenas por França, Grã-Bretanha, Itália e Japão como membros permanentes, e Brasil, Bélgica, Espanha e Grécia como membros não permanentes reelegíveis até que fosse aprovada uma cláusula de revezamento que ficou conhecida como roulement. O Conselho era responsável pelas decisões sobre as mais relevantes questões internacionais, como os conflitos políticos. Cada membro do Conselho tinha igual poder de veto, e um veto seria suficiente para impedir qualquer aprovação.

Na década de 1920, se a sociedade internacional passava por essas mudanças estruturais, a sociedade brasileira vivia o que Helena Lorenzo ${ }^{5}$ chamou de "aceleração da história", com a emergência da classe operária, da militar e de camadas médias urbanas, bem como os efeitos da Segunda Revolução Industrial. O fortalecimento do papel do Estado na solução da crise política e econômica, tanto a internacional quanto a brasileira, foi uma constante nesse período. É neste momento que o governo Arthur Bernardes desenvolve o plano de assegurar ao Brasil um assento permanente no Conselho da Liga das Nações como estratégia de política externa e interna. Durante o governo de Epitácio Pessoa, o Brasil defendeu assento permanente no Conselho como uma "demanda justa", mas sem grandes pretensões. O governo Bernardes, porém, transformou a campanha em verdadeira missão, usando o conceito de "direito natural", para legitimar a candidatura do Brasil.

Nos Acordos de Locarno, feitos, secretamente, entre os membros permanentes da Liga, a Alemanha ganhou prioridade como candidata a membro permanente, sinalizando

\footnotetext{
${ }^{4}$ HERZ, Mônica; HOFFMANN, Andréa Ribeiro. Organizações Internacionais. São Paulo:Elsevier, 2004. p.13

${ }^{5}$ LORENZO, Helena Carvalho de. A década de 1920 e as origens do Brasil moderno. São Paulo: UNESP, 1997.p. 186 .
} 


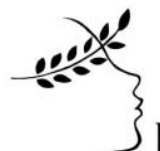

um perigo para a campanha brasileira. Buscando impedir que a Alemanha entrasse como permanente, e não o Brasil, Bernardes manda vetar a entrada da Alemanha, causando grande polêmica internacional e ignorando as opiniões dos diplomatas brasileiros contrários ao veto. Em uma nova eleição, a Alemanha foi aprovada, e o Brasil retira-se voluntariamente do Conselho, repudiando a atitude europeia e provocando uma crise diplomática, em 1926. Estudar as razões e as repercussões internas e externas dessas decisões brasileiras será o objeto do presente trabalho. A candidatura brasileira a membro permanente iniciou-se no governo de Epitácio Pessoa (1919-1922), continuando no governo Bernardes (1922-1926). O veto brasileiro à entrada da Alemanha na Liga ocorre em sete de março de 1926, e esse ano também é o último do governo Bernardes.

\section{A América Latina após a Primeira Guerra Mundial}

A inteligência naval brasileira desenvolveu durante a década de 1920 vários estudos certificando que o Brasil se encontrava em situação de inferioridade bélica naval em relação aos seus vizinhos. Já os países da América Latina, após a Primeira Guerra Mundial, tornaram-se muito mais cautelosos sobre qualquer política armamentista brasileira, sendo a própria presença do Brasil na Liga das Nações motivo suficiente para gerar desconfiança sobre uma possível política de hegemonia regional garantida pela nova importância internacional adquirida.

O Brasil sofreu isolamento diplomático nas discussões sobre segurança na América Latina devido à sua posição positiva sobre o armamento. Esse isolamento não ocorreu apenas na Liga das Nações, sendo bastante visível na Conferência Pan-americana de Santiago em 1923, no âmbito regional. Quem convocou essa Conferência foi o Chile com a intenção de gerar um consenso regional sobre a necessidade de limitarem-se os gastos navais no continente, a chamada tese $\mathrm{XII}^{6}$. O Brasil iniciou processo de uma

\footnotetext{
${ }^{6}$ GARCIA, Eugênico Vargas. Revista Brasileira de História. A diplomacia dos armamentos em Santiago: o Brasil e a Conferência Pan-americana de 1923. São Paulo, v. 23, nº 46, pp. 173-200 - 2003.
} 
Missão Militar Francesa para modernizar o exército e uma missão naval com os Estados Unidos. Essa política brasileira gerou tensões no plano estratégico de forças entre Brasil, Argentina e Chile conhecido como ABC, o equilíbrio estratégico sul-americano. As tensões datam principalmente de 1906, quando o programa naval brasileiro requisitava a construção de três encouraçados do tipo dreadnought, construídos na Inglaterra. Ficaram prontos em 1910, e, em 1911, a Argentina encomendou dois encouraçados dos Estados Unidos, e o Chile, logo depois, também, dois, da Grã-Bretanha. Estava formada uma corrida armamentista. Os gastos foram cortados com a eclosão da Grande Guerra, mas logo depois as discussões voltaram à tona com a contestação do Estado Maior do Exército, por meio de estudos secretos, de que o Brasil era o país menos armado do ABC.

A partir dessa constatação, o Brasil verificou que, pelo artigo oitavo do Pacto da Liga das Nações, havia legalmente autorizado no Pacto um mínimo de poder bélico autorizado aos membros da Liga que fosse compatível com as necessidades de defesa. Esse "mínimo compatível brasileiro estaria, então, pelas análises navais, desequilibrado. Em 1922, já ocorria a Conferência Naval de Washington que visava estabelecer limitações de tonelagem, quando o presidente Epitácio Pessoa pediu que o Brasil não aceitasse nenhuma limitação naval. Brasil tentou marcar uma reunião prévia com Argentina e Chile, conduzida por Félix Pacheco, para atingir consenso, mas a Argentina agiu hostilmente à ideia, por se considerar inferior ao Brasil e ao Chile nos seus armamentos navais, e os jornais argentinos passaram a denunciar o "imperialismo brasileiro".

Argentina propôs que o Brasil se limitasse à tonelagem de 55.000, mas os três encouraçados que o Brasil tinha já pesavam 44.000. O Brasil resolveu abster-se de qualquer fórmula que limitasse seu poder naval diante de todos e quaisquer propostas feitas durante a Conferência de 1923. A Argentina elevou sua campanha de imprensa a níveis hostis à posição brasileira e também o passou a fazer o Chile. Nessa atmosfera de hostilidade, corrida armamentista e conferências frustradas por falta de consenso, o Brasil saiu diplomaticamente isolado. Esse isolamento foi sentido bastante na Liga das Nações, em que a diplomacia latino-americana teve outro papel fundamental na definição das estratégias brasileiras. Vamos ao estudo dessa outra realidade de tensões. 


\section{Novas fontes de pesquisa e novas problemáticas sobre as tensões diplomáticas entre Brasil e países da América Latina.}

A busca pelo assento permanente na Liga iniciou-se no governo Epitácio Pessoa, como forma de o Brasil manter-se na organização visto o claro perigo de não conseguir se reeleger como membro temporário. Havia uma regra chamada de roulement ${ }^{7}$, presente no pacto de Paris, que determinava que em tempo ainda a ser determinado, os membros não permanentes deveriam ser trocados. O Brasil, portanto, busca se tornar permanente antes que esse período do roulement começasse a viger. Essa busca, porém, não era apenas brasileira. Na verdade, vários países da América Latina também ansiavam por representação na Liga. O desejo de autonomia desses países latinos contrastava com o argumento brasileiro de ser o Brasil o legítimo representante do continente americano após a saída dos Estados Unidos; esse anseio dos vizinhos latinos passou a representar um constante perigo a qualquer proposição brasileira nas mais diversas conferências.

As tensões regionais europeias dentro da Liga ficaram muito claras na historiografia atual, mas muito pouco ou nada se tem analisado sobre as tensões latinoamericanas. As razões para a busca pelo lugar permanente para o Brasil na Liga, contudo, passa, necessariamente, pelas rivalidades secretas e pelos planos arquitetados nos bastidores da diplomacia latino-americana contra o Brasil. Essa é uma importante novidade na historiografia sobre a participação brasileira na Liga das Nações. Os países latinos que estiveram na Liga, em vários momentos, agiram contra o Brasil, e essa pressão foi fundamental para determinar a ação brasileira em sua busca por um lugar entre as grandes potências. Para investigarmos as intrigas secretas da diplomacia americana, acompanharemos o desenvolver cronológico de vários embates, analisando caso a caso.

\footnotetext{
${ }^{7}$ GARCIA, Eugênio Vargas. (2000), O Brasil e a Liga das Nações (1919-1926). Porto Alegre, Editora da UFRGS.p. 70.
} 
O principal objetivo da delegação brasileira na Liga era mostrar que o Brasil poderia contribuir nas mais importantes temáticas para angariar respeito à imagem da América Latina. Desde o início da Liga, a imagem brasileira vinha sendo associada à América Latina, pois o próprio Brasil forçara essa situação com seu argumento de legítimo representante do continente depois da saída dos Estados Unidos. A América Latina, porém, não trazia ao Brasil muitas vantagens comparativas. Analisamos uma carta confidencial do delegado brasileiro, major Barbosa Carneiro, a Arthur Bernardes reportando a segunda Conferência de Transportes, em 1923, quando um dos delegados, Sr. Comert anunciou: “A América Latina é temida, mas não é respeitada na Sociedade das Nações. Não são respeitados porque nunca trouxeram uma idéia à Sociedade no terreno dos princípios, limitando-se a disputar posições e a pedir cargos. Seus representantes não estudam as questões e apenas cuidam de questões eleitoraes" ${ }^{8}$.

O delegado brasileiro, Afrânio de Melo Franco, interpelou o palestrante Comert, que reconheceu publicamente que o Brasil era o único representante latino a contribuir para as questões, por exemplo, as de trânsito, e que suas opiniões eram muito respeitadas. Comert citou um episódio em Barcelona no qual o Brasil "foi mediador de primeira

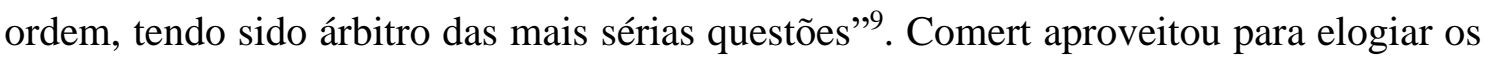
conhecimentos jurídicos expostos pelo Brasil, declarando ainda: "quando eu falava da América Latina, eu considerava o Brasil à parte" ${ }^{10}$. As nações latinas ficariam, assim, "mordidas" pela crítica pública e pelo elogio ao Brasil. Nesse relatório, ficou claro que o Brasil já começava a pagar o preço por ser uma nação "à parte da América Latina". Alguns países latino-americanos passaram a movimentar-se contra o Brasil em várias situações.

O major Barbosa, militar da marinha, técnico do Brasil na Liga, informou, em telegrama, ao presidente, que Cuba e Chile fizeram oposição para a renovação do Brasil

\footnotetext{
${ }^{8}$ Major Estevão de Carvalho a Arthur Bernardes, Carta confidencial. 5 fevereiro de 1924.APM cx.119. ${ }^{9}$ Id., p. 2

10 Major Estevão de Carvalho a Arthur Bernardes, Carta confidencial. 5 Fevereiro de 1924.APM cx.119.p.4.
} 
como membro permanente da Comissão de Trânsito, no fim daquela conferência ${ }^{11}$. Além dessa oposição, o major supunha que houvesse outra chapa, uma secreta entre Uruguai e Chile, que também se organizava contra o Brasil. O presidente dessa comissão de transportes era o delegado Medina, do Uruguai, que foi indicado pelo próprio Brasil. O major Carneiro explicou ${ }^{12}$, porém, que, desde o início dessa conferência, Medina, do Uruguai, manifestou inegável hostilidade a tudo que o Brasil propunha. O Brasil, na Conferência de Transportes, estava enfrentando a oposição de Cuba e Chile, hostilidades do presidente da Comissão, delegado do Uruguai, e uma coalizão secreta contra a presença brasileira entre Uruguai e Chile. A leitura da ata dessa conferência confirma que realmente o Uruguai vinha votando contra as proposições do Brasil sobre os mais diversos assuntos e não faria sentido o major Barbosa mentir ao presidente em telegramas confidenciais, portanto realmente tudo indicava uma organizada oposição latinoamericana às propostas brasileiras na Conferência de Transportes.

Os resultados dessa citada coalizão secreta ficaram expostos na Conferência sobre Eletricidade. Em uma subdivisão da comissão para transportes que ocorreu no mesmo período, no ano de 1923, estava para ser aprovada uma cláusula, vinculando, ao menos moralmente, seus membros de iniciarem-se as negociações a respeito do aproveitamento de quedas d'água em seus territórios para fins de geração de energia elétrica ${ }^{13}$. A delegação brasileira sofria um impasse: se assinasse a convenção, o governo teria que iniciar negociações com a Argentina sobre as quedas d'água de Iguaçu. Os delegados brasileiros, porém, estavam sem receber instruções do governo brasileiro, enquanto o delegado da Suíça apresentou-se muito animado com a possível assinatura, pois era, também, representante de um dos maiores investidores nos bancos de Buenos Aires e lucraria com a nova atividade. A pressão para a continuidade dos acordos foi grande, e quase se iniciou, ali mesmo, as tratativas do acordo entre Brasil e Argentina, visando o aproveitamento das quedas de Iguaçu.

\footnotetext{
${ }^{11}$ Major Barbosa Carneiro a Félix Pacheco 8 de dezembro de 1923, Relatório Confidencial sobre a Comissão de Trânsito e Energia. APM. Cx.119. p.1.

12 Id., p. 3.

${ }^{13}$ Major Barbosa Carneiro a Félix Pacheco 8 de dezembro de 1923, Relatório Confidencial sobre a Comissão de Trânsito e Energia. APM, cx119. p.5.
} 
Com receio de prejudicar as estratégias políticas do governo, porém, Montaroyos, delegado brasileiro, decidiu não assinar. Naquele momento, a Argentina não era membro oficial da Liga por não ter ratificado o pacto dessa organização, mas participou da Convenção de Energia e de Trânsito isoladamente; demonstrava-se apta a conversar sobre o empreendimento em Iguaçu, mas o Brasil recusou continuar a negociação. Findava ali, tanto por receios políticos dos delegados brasileiros de perderem vantagens estratégicas em negociar sem amplos estudos quanto pela falta de orientação vinda do presidente a respeito do assunto, um plano de integração latina que irá se desenvolver apenas em 1979, durante governo Geisel pelo acordo Itaipu-Corpus. O mais interessante nessa conferência, entretanto foi a posição dos latino-americanos.

Enquanto o Brasil estava apertado com a falta de instruções do governo, o próprio líder da Conferência de Energia, o Uruguai, sofria uma pressão secreta por parte de seus aparentes aliados latinos: as tratativas que o Uruguai vinha organizando nessa conferência de energia não deram certo, pois Cuba e Chile votaram contra a cláusula de obrigatoriedade, ao menos moral, em iniciarem-se negociações sobre quedas d'água. $\mathrm{O}$ Uruguai era o presidente da Convenção graças ao voto do Brasil, que via um país menor da América Latina na liderança como símbolo de respeito ao que a Europa fizera antes, elegendo também um país menor, no caso, a Holanda. Como presidente da comissão, o plano Uruguaio era fazer aprovar as convenções de energia e seus transportes. Se havia uma inteligência geopolítica uruguaia, visando causar alguma contenda entre Brasil e Argentina devido a Iguaçu ao forçar a aprovação da cláusula de negociação de recursos hídricos, não podemos afirmar, mas, mesmo que houvesse, o delegado do Uruguai não conseguiu levar seus planos adiante. Uruguai não alcançou a aprovação da cláusula sobre quedas d'água, nem sua pretendida reeleição devido à oposição de seus próprios aliados: Chile e Cuba, uma reviravolta no sistema de alianças então firmado.

Os outros latinos nessa convenção, de acordo com o major Barbosa Carneiro ${ }^{14}$, Chile e Cuba, se opuseram à continuidade do Uruguai na presidência da convenção e o

\footnotetext{
${ }^{14}$ Major Barbosa Carneiro a Félix Pacheco 8 de dezembro de 1923. Relatório Confidencial sobre a Comissão de Trânsito e Energia. APM cx.119. p. 7.
} 
secretariado aceitou os argumentos da nova oposição latina: “o secretariado discretamente invocou o argumento das compensações: o Brasil e o Uruguai já faziam parte do Conselho, seria justo dar postos a outros países latino-americanos". ${ }^{15}$ Para conquistar lugar na comissão, Aguero, delegado de Cuba, "ao mesmo tempo que simulava trabalhar em favor do Brasil, o fazia em favor de Chile, pois a sua chapa real era Cuba-Chile." ${ }^{16} \mathrm{O}$ representante do Uruguai, iniciada a Conferência de Energia, percebeu que Cuba e Chile trabalhavam não apenas contra o Brasil, mas, também, contra o próprio Uruguai.

O Uruguai, dessa maneira, mesmo após toda sua oposição ao Brasil no início da Conferencia de Trânsito, passou a buscar uma aliança conosco, para frear a frente CubaChile, firmando-se, assim, dois lados que se opuseram no momento das votações, Uruguai-Brasil de um lado e Cuba-Chile de outro, impedindo unanimidade latinoamericana sobre todos os assuntos da Conferência de Energia, como narra o major Barbosa ao presidente Bernardes ${ }^{17}$. Por fim, haveria uma votação para o próximo presidente da Comissão de Energia na Liga. No resultado da votação, o Brasil empatou com o Chile, e houve mais uma segunda votação quando o Chile obteve quatro votos a mais do que o Brasil. De acordo com major Carneiro, esses quatro votos eram da Venezuela, Chile, Cuba e Colômbia, configurando assim, uma derrota para Brasil e para o Uruguai devido à oposição de seus próprios vizinhos latinos. O delegado que esteve o tempo todo a favor do Brasil foi Guerrero, do Salvador. O major expôs em sua carta ${ }^{18}$ que Salvador informou tudo secretamente ao Brasil e foi assim que a diplomacia brasileira pôde descobrir que, desde o início, o Chile estava tramando um plano contra a eleição brasileira, mesmo demonstrando constante e simulada amizade.

Guerrero, delegado do Salvador foi, então, quem abriu os olhos do major quanto ao plano secreto de Cuba e Chile. Informou que, desde 1922, Cuba vinha planejando apoiar a candidatura do Uruguai e depois do Brasil para que esses dois pudessem sair

\footnotetext{
${ }^{15}$ Id., p.3.

${ }^{16}$ Major Barbosa Carneiro a Félix Pacheco 8 de dezembro de 1923. Relatório Confidencial sobre a Comissão de Trânsito e Energia. APM cx.119. p 10

${ }^{17}$ Major Barbosa Carneiro a Félix Pacheco 8 de dezembro de 1923. Relatório Confidencial sobre a Comissão de Trânsito e Energia. APM cx.119. p.11

${ }^{18}$ Major Barbosa Carneiro a Félix Pacheco 8 de dezembro de 1923. Relatório Confidencial sobre a Comissão de Trânsito e Energia. APM cx.119. p13.
} 
juntos da comissão e facilitar a aprovação de Cuba e Chile, por isso mesmo Cuba vinha, desde 1922, mostrando-se favorável ao Brasil. Os delegados Aguero, de Cuba, e Edwards, do Chile, estavam, portanto trabalhando em conjunto não apenas com os latinos. Guerrero, esse informante secreto do Brasil, contou ao major que a aliança Cuba-Chile trabalhou em propaganda para as nações europeias e aos Estados Unidos, pedindo por mais presença e representação na Comissão de Transportes em favor deles, obtendo êxito. Guerrero provou ao major brasileiro que vários países europeus já vinham felicitando a aliança entre Edwards e Aguero ${ }^{19}$, consumando o sucesso do plano Chile-Cuba.

O major brasileiro, diante desse quadro de alianças secretas, emitiu sua opinião a Félix Pacheco:

\begin{abstract}
é indispensável que o Brasil se precavenha contra essa manobra e a melhor resposta é a sua entrada como membro permanente do Conselho. É preciso não desconhecer que a situação é perigosa. O trabalho nas chancelarias é urgente (especialmente Londres, Paris e Washington que agem aquelles sobre a Europa e este sobre as republicas hispano-americanas. Trabalho urgente. Os meios de realização desse programa poderiam ser: a) conservação de um membro permanente das delegações em todas as assembleias. b) creação, no Itamaraty, de um serviço especial para a Sociedade das Nações ${ }^{20}$.
\end{abstract}

Além dessas duas sugestões, o major enviou um esquema completo de reestruturação para a relação entre o Itamaraty e a Sociedade das Nações. A preocupação desse representante do Brasil ficou nítida. O major deve ter ficado muito surpreso com tamanho esforço latino-americano contra as posições do Brasil. Se não fosse a amizade salvadorenha, o Brasil nunca saberia o longo jogo que Cuba e Chile vinham arranjando contra a delegação brasileira na Convenção. Essa intriga latino-americana ocorreu nas tratativas dos mais diversos assuntos que relacionam o Brasil na Liga, não apenas na comissão de trânsito e de energia, como veremos a diante. Fica, desse modo, muito claro que a busca pelo lugar permanente para o Brasil na Liga estava associada à própria sobrevivência de quaisquer propostas brasileiras nas mais variadas temáticas, pois os

\footnotetext{
${ }^{19}$ Major Barbosa Carneiro a Félix Pacheco 8 de dezembro de 1923. Relatório Confidencial sobre a Comissão de Trânsito e Energia. APM cx.119. p.11

${ }^{20}$ Major Barbosa Carneiro a Félix Pacheco 8 de dezembro de 1923. Relatório Confidencial sobre a Comissão de Trânsito e Energia. APM cx.119.13
} 


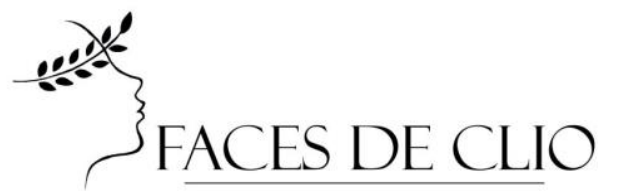

esquemas secretos latino-americanos se revelaram muito difíceis de identificar e vinham minando as votações de muitas comissões que o Brasil participava.

As propostas brasileiras na Comissão de Transportes foram hostilmente tratadas pelo Uruguai e amistosamente recebidas por Cuba e Chile, mas quem realmente queria ver o Brasil fora do jogo junto com o Uruguai eram Aguero e Edwards. Os representantes brasileiros devem ter ficado ainda mais surpresos quando Guerrero os contou que os planos de Cuba-Chile datavam de 1922, dois anos antes daquela votação. A sugestão do major brasileiro a Félix a respeito do lugar permanente e as ameaças latinas, cada vez mais nítidas, às propostas brasileiras certamente deram novos contornos estratégicos e geopolíticos para a conquista do lugar permanente na Liga. Por meio da Liga das Nações, o Brasil poderia ter uma autoridade internacional reconhecida pelas grandes potências; autoridade que os latinos nunca poderiam contestar, nem se oporem. O lugar permanente no Conselho confirmaria o Brasil como um país "à parte da América Latina", dando aos brasileiros uma posição geopolítica regional sem precedentes nos jogos de força latinoamericanos. Ser um membro permanente passou a ser uma solução não apenas parte de um plano regional para se ter mais supremacia geopolítica, mas, principalmente, uma forma de fazer sobreviver qualquer brasileira naquelas assembleias. As hostilidades latino-americanas não poderiam ser expostas ao público, pois o argumento brasileiro era justamente baseado em sua legitimidade como representante da América. Portanto, ser membro permanente, mais que antes, era a única solução.

Seria muito inocente acreditar que Félix e Bernardes não ouviram os fortes apelos do major. O representante brasileiro demonstrou ainda mais sobre sua estratégia, no fim da longa carta:

Há uma opinião pessimista que julga inútil o Brasil na Sociedade das Nações. É isso um grave erro. Assim como a Inglaterra e a França sabem servir-se della para a sua política internacional, também o Brasil e sua esphera, pode tirar grande proveito dessa machina (...) será por intermédio dela que mais facilmente as republicas iberoameicanas figurarão no concerto mundial. Cumpre-nos ganhar terreno para ser a primeira, a mais considerada dentre as nações americanas no seio da Sociedade, e assim alcançarmos vantagens que se traduzirão 
nas reações mais salutares sobre a política sul-americana de que nos cabe ser árbitro ${ }^{21}$.

Nesse último trecho, vemos claramente exposta a estratégia que vincula o assento permanente no Conselho à geopolítica sul-americana do major, tratando a Liga como máquina da nova política internacional que deveria ser usada para os fins das políticas regionais. Assim como França e Inglaterra estavam instrumentalizando a Liga para equilibrar seus interesses regionais, o Brasil também deveria fazê-lo. Diante dessa estratégia de aliar os interesses regionais do Brasil à autoridade internacional, a insistência da diplomacia brasileira em se firmar como legítima representante dos americanos, um argumento aparentemente muito defasado e com muitas dificuldades em ser aceito, ganha um novo significado. Garantir seu lugar como membro temporário no Conselho não seria suficiente; o Brasil precisava, também, assegurar a aceitação latina a essa autoridade.

$\mathrm{O}$ argumento de ser o Brasil o representante legítimo dos americanos enfrentou muitos obstáculos. Alguns historiadores, inclusive, se questionaram sobre por que Melo Franco insistia tanto nessa linha de raciocínio. Diante das nítidas dificuldades brasileiras com as oposições dos latino-americanos às suas propostas, fica claro, porém, que ser reconhecido como legítimo representante na América pela Sociedade das Nações não era, na prática, uma forma de mostrar integração latina, mas de impor aceitação regional à autoridade brasileira. Com o apoio das grandes potências às diretrizes brasileiras, como a necessidade de armar-se mais, tornaria muito difícil a continuação da histórica oposição que os latinos sempre fizeram aos avanços bélicos do Brasil. O argumento de legítimo representante americano não nos parece ser, portanto, um resultado da aceitação latina diante dos auspícios da política externa do Brasil, mas, antes, uma forma de o Brasil gerar aceitação dos latino-americanos mediante uma inquestionável autoridade internacional que ganharíamos por estarmos no Conselho da Sociedade.

\footnotetext{
${ }^{21}$ major Estevão de Carvalho a Arthur Bernardes, Telegrama confidencial. 7 de fevereiro de 1924. APM cx.119. p.14.
} 


\title{
Uma nova investida: a reação brasileira após as ameaças da diplomacia latino- americana.
}

O delegado brasileiro que estava à frente da representação brasileira era Clarck, mas o plano de Félix Pacheco foi de trocá-lo por Afrânio de Melo Franco, que vinha sendo ministro das finanças do governo, cargo que sempre exigiu proximidade e confiança por parte do presidente. Afrânio foi convidado a assumir a representação da delegação brasileira na Sociedade das Nações, e, para isso, os gastos com a representação brasileira subiram consideravelmente. Esse plano partiu do próprio Félix Pacheco, que, em 11 de março de 1924, anunciou importantes mudanças no quadro de embaixadores:

\begin{abstract}
A nossa verba "Extraordinários no Exterior", mais bem dotada esse anno, comporta a despeza que tivermos que fazer com pessoal (...) Esse pessoal terá residência obrigatória na sede da Liga (...) com uma organização assim e os vencimentos de embaixador, não creio que o Dr. Afrânio recusasse o posto. (...) a tarefa vae ser mais difícil que ano passado quando já o Chile nos quis ardilosamente applicar a regra do roulement, manejo que o Edwards vae certamente repetir e dessa vez. com maior probabilidade de êxito se não tivermos em Londres uma figura idônea e diligente para enfrentar com vantagens esse nosso encapotado e impenitente adversário (fala do representante da Inglaterra) que tão mal interpreta os sentimentos de seu paíz em relação ao Brasil $^{22}$.
\end{abstract}

Logo mais, após nomear a troca de alguns embaixadores que também julgou estratégica para a conquista do lugar permanente, enfatizando que a principal mudança seria a retirada do embaixador Domício da Inglaterra, colocando em seu lugar o embaixador Amaral, Félix escreve: "com o embaixador Amaral em Londres, confio muito em que poremos a Inglaterra de nosso lado na Liga, annulando os manejos subterrâneos de Edwards" 23. Veja como a preocupação de Pacheco em reformar o quadro de embaixadores passava tanto pela estratégia de reforçar a busca pelo assento permanente quanto de superar a diplomacia chilena que, a esse ponto, ficou claro ser inimiga da brasileira na Liga. Pelo telegrama de Félix a Bernardes, constata-se como a preocupação

\footnotetext{
${ }^{22}$ Telegrama de Félix Pacheco a Arthur Bernardes, 11 de Março de 1924 APM. Cx.119.

${ }^{23}$ Telegrama de Félix Pacheco a Arthur Bernardes, 11 de Março de 1924 APM. Cx.119. p.3
} 
com os obstáculos da diplomacia regional andava junto à busca pelo lugar permanente. A diferença era que agora o Brasil estava reagindo a esse obstáculo. Domício era considerado um diplomata velho e pouco eficiente diante justamente da Inglaterra. Uma vez que o Brasil conseguisse o apoio Inglês, a possibilidade de alcançar o lugar permanente seria muito maior.

Em 26 de março de 1924, a mudança sugerida pelo major Carneiro e executada por Félix foi sentida. Os diplomatas argentinos reclamaram sobre o Brasil estar instalando uma embaixada na Liga. O plano brasileiro era ter uma representação permanente na Liga muito semelhante a uma embaixada. Isso parece ter incomodado a Argentina, pois, nessa data, Afrânio enviou uma carta pessoal a Arthur:

Pelos telegramas de Buenos Aires, vejo que nem todos compreenderam as ações do Brasil (...) supõe alguns que nós creamos uma embaixada junto à Sociedade, quando o que creamos foi uma delegação permanente cujo chefe tem os horários, prerrogativas, títulos $e$ vencimentos e um embaixador (...) não é justamente a criação de uma embaixada. ${ }^{24}$

Em agosto de 1924, a reação brasileira já tinha começado. Raul Fernandes foi até a Suécia e à Áustria, para convencer seus delegados a serem favoráveis ao Brasil como membro permanente na Liga. De acordo com Raul, o representante da Áustria estava convencido em apoiar o Brasil ou ao menos em não se opor à sua candidatura, completou Raul, dizendo: "a sua opposição, tão temida pelo Afrânio, desapareceu"25. Raul expôs que sua esperança era levar à Inglaterra a confirmação de intenção de voto favorável ao Brasil de outros países europeus, para forçar os ingleses a não serem contra devido ao apoio dos vizinhos da ilha. Raul afirmou: "em resumo, minha expectativa é de que venceremos"26. Fernandes ainda fez uma visita em propaganda pelo Brasil na Bélgica,

\footnotetext{
${ }^{24}$ Afrânio de Melo Franco a Arthur Bernardes, 26 de março de 1924, carta pessoal. APM cx.119. p.2. Essa carta desfaz, inclusive, uma errada suposição da própria historiografia que afirma que o Brasil abriu uma representação com o status de embaixada. Foi, na verdade, uma delegação permanente como afirma Franco diretamente ao presidente em sua carta.

${ }^{25}$ Raul Fernandes a Félix Pacheco, telegrama confidencial. 21 de agosto de 1924. APM cx119.

${ }^{26}$ Raul Fernandes a Félix Pacheco, telegrama confidencial. 22 de agosto de 1924. APM cx119.
} 
Holanda e Tcheco-eslováquia, sempre reportando positivamente sobre a possibilidade desses países apoiarem o pleito brasileiro ${ }^{27}$.

E aliados? Tínhamos algum? O Brasil tinha um importante aliado em suas propagandas nas chancelarias, a França. O interesse geopolítico francês não era explicitamente comentado nos telegramas, nem nas cartas confidenciais entre diplomatas e Félix ou Bernardes, mas sabemos que o principal interesse da França em apoiar o pleito brasileiro era devido à sua estratégia geopolítica regional: evitar o retorno da Alemanha ao jogo da balança de poder europeia, fazendo valer a ideia de país derrotado e sem direitos. A velha disputa de forças entre França e Alemanha simplesmente continuava por meio, agora, da Sociedade das Nações, e o apoio francês ao Brasil, em vez de à Alemanha era parte dessa estratégia. A França apoiou os pleitos do Brasil, da Espanha e da Polônia como candidatos a membros permanentes. O principal interesse francês era na candidatura da Polônia, geograficamente e culturamente mais próxima da Alemanha, a Polônia era claramente estratégica no balanço de forças europeias. Tanto era que a invasão desse país pela Alemanha desencadeará, no futuro, a Segunda Guerra Mundial. Não façamos, porém, teleologismo. Ao Brasil, a França sempre prestou auxílio, inclusive tentando convencer Léon a favor da nossa candidatura. Clarck declarou: "a França procedeu conosco como verdadeira amiga, fazendo cabala por nós junto a todas as Delegações para a reeleição" 28 .

Sobre os latino-americanos, Clarck disse que a maioria declarava apoio reticente ao Brasil, mas que Aguero, de Cuba, trabalhava junto aos países europeus a favor do roulement e a favor de sua própria candidatura, bem como o Chile, com seu delegado Guani. O delegado brasileiro comunicou ao presidente estar ciente de que vários pequenos países europeus disseram-lhe sobre o desejo de votarem a favor da inteira renovação dos membros não permanentes. Afirmou Clarck: "o que quer dizer que teríamos que lutar contra Chile e Cuba o que seria altamente inconveniente a nossa política americana. ${ }^{29,}$ Diante disso, Clarck faz uma proposta: "sugeri o bonito gesto de o Brasil renunciar a seu

\footnotetext{
${ }^{27}$ Raul Fernandes a Félix Pacheco, telegrama confidencial. 22 de agosto de 1924. APM cx119.p.3.

${ }^{28}$ Clarck para Félix Pacheco, telegrama confidencial. 4 de outubro de 1924. APM. cx 119. p.4

${ }^{29}$ Clarck para Félix Pacheco, telegrama confidencial. 4 de outubro de 1924.p.7 APM cx119.
} 


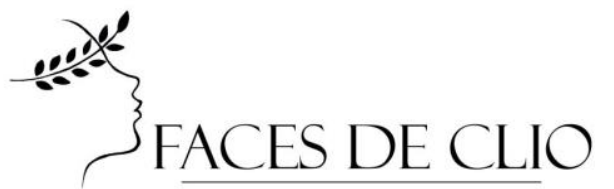

mandato sugerindo um país americano qualquer" ${ }^{30}$. Parecia que o delegado brasileiro estava desistindo da campanha a membro permanente.

A amizade com a França, porém, começou a mostrar resultados. O delegado brasileiro disse, em carta ao presidente ${ }^{31}$, ter amizade forte com membros da delegação francesa: Clangel, Jouvenel e Boncour. Clangel vinha secretamente informando Clarck de que o Chile pedia Lord Parmoor, da Inglaterra, para fazer valer o roulement. O representante brasileiro, então, pediu ajuda aos franceses para que persuadissem Aguero, de Cuba, e também o Chile a desistirem de suas candidaturas. Essa manobra de Clarck funcionou. Boncour interpelou Aguero pessoalmente para que ele deixasse de insistir na candidatura de Cuba e o delegado cubano cedeu. Apesar da vitória, o ministro chileno Villegas questionava Clarck via cartas constantemente sobre a insistência brasileira na não efetivação do roulement, pois, se essa regra realmente valesse, o Brasil já teria que ter saído do posto no Conselho. Troca de cartas, dissimulações, planos secretos, propagandas trocadas e informantes confidenciais, tudo isso nos ajuda a reconstruir o ambiente de pressões diplomáticas que se avultava diante dos anseios brasileiros em ser membro permanente no Conselho. A maior pressão certamente vinha da América Latina.

A estratégia do Chile era a mais hostil e perigosa ao pleito brasileiro. Por meio de Lord Parmoor, o Chile quase convenceu a Inglaterra a fazer forçar o roulement, o que o Brasil no Conselho ali mesmo e tudo estaria perdido, mas foi o interesse francês que, mais uma vez, fez a diferença para a permanência brasileira. Quem informou sobre os planos secretos do Chile a Clarck foi o delegado francês que ficou sabendo da trama chilena pelo próprio Parmoor ${ }^{32}$. Foi Briand, o famoso delegado francês que conseguiu dissuadir o velho de oitenta anos, Lord Parmoor, a não prosseguir com os planos de fazer valer o roulement. Por um triz, o Brasil acabou salvando sua estadia no Conselho para $1925^{33}$. Foi realmente a França quem mais se opôs a toda mudança no status quo do quadro de membros do Conselho, afinal os interesses de sua diplomacia regional, como já dissemos,

\footnotetext{
${ }^{30}$ Clarck para Félix Pacheco, telegrama confidencial. 4 de outubro de 1924. APM. cx 119 p.7

314 Clarck para Félix Pacheco, telegrama confidencial. 4 de outubro de 1924. APM. cx 119 p.8.

${ }^{32}$ Telegrama de Clarck para Félix Pacheco. 4 de outubro de 1924. APM CX.119 p.10.

${ }^{33}$ Telegrama de Clarck para Félix Pacheco. 4 de outubro de 1924. APM CX.119 p.11.
} 
concorriam exatamente para o sentido de manter as pressões sobre a Alemanha e pela independência da Polônia, membro também candidato a permanente.

O Brasil precisava fazer alguma coisa sobre esses planos do Chile e de Cuba que continuavam secretamente buscando apoio na Inglaterra. Uma das mais importantes insistências dos latinos quanto ao Brasil era o aceite brasileiro à convocação de uma reunião latino-americana para discutir a Liga e a diplomacia da segurança da região. Clarck defendia que o Brasil devia aceitar como forma de tentar alcançar a tão necessária coesão latina: "procurei Dr. Afrânio para convencê-lo a convocar, de acordo com o pedido do Guani, uma reunião dos latino-americanos"34. Essa reunião ocorreu no gabinete da delegação chilena quando, finalmente, Aguero aceitou renovar o voto cubano junto com o chileno para a permanência do status quo para 1925. F. Clarck, por fim, declara: "ficou bem patente que só graças às decisões das Grandes Potências é que o status quo foi mantido este anno, e que a reeleição do Brazil foi devido, sobretudo, à mediação da França, em nosso favor, não só junto à Grã-Bretanha, como junto aos próprios latinoamericanos" $" 35$.

Foi assim, com essa manobra de Clarck e da delegação francesa que o Brasil conseguiu convencer Chile e Cuba a manter seus votos favoráveis ao não roulement, bem como convencer a Inglaterra sobre essa permanência do quadro de membros. Veja como os votos latinos fizeram toda a diferença na formação da diplomacia brasileira na Sociedade das Nações. Essa pressão da oposição cubana e chilena convenceu a diplomacia brasileira que a única chance para o Brasil era efetivamente se tornar membro permanente. Por mais que esse fosse um plano já no final do governo de Epitácio Pessoa, a transformação da conquista ao lugar permanente em prioridade da política externa de Bernardes ocorreu principalmente devido a esse ambiente de hostilidades regionais. Ser membro temporário diante de tantos planos secretos por parte dos latinos não era mais uma opção. A decisão de transformar a campanha brasileira à cadeira permanente em uma verdadeira missão diplomática, não partiu, portanto, do próprio governo Bernardes, mas

\footnotetext{
35 Telegrama de Clarck para Félix Pacheco. Condifencial. 4 de outubro de 1924. APM. Cx 119.p.8
}

\begin{tabular}{l|l|l|l} 
VOL. 4 & N.7 & JAN/JUN. 2018
\end{tabular} 
das circunstâncias incontornáveis para a sobrevivência do Brasil na Liga. Como afirmará Clarck sobre o Brasil em 1925 na Liga: "não devemos pleitear nossa reeleição, mas apenas nossa permanência" 36 .

Se até então os países vizinhos eram quem armavam mais intrigas ao Brasil, após a reunião que tiverem no gabinete chileno, a integração latina funcionou pela primeira vez a todo vapor em direção ao plano de manter o Brasil para 1925. Aguero transformouse de ardiloso estrategista para "verdadeiro sentinela da victória" ${ }^{37}$. Aguero distribuiu ele mesmo os panfletos da propaganda brasileira. "Ainda no dia da eleição, o Villegas (ministro espanhol) mostrou ao Dr. Afrânio um telegrama de Lord Parmoor, declarando que só pelo facto delle, Villlegas, have-lo informado da decisão do grupo latinoamericano de votar no Brasil, é que elle deixava de votar no Chile, raro exemplo de inconsequência em um homem de 80 annos!" 38 Por essas esclarecedoras palavras de Clarck, podemos compreender como o comportamento da diplomacia inglesa era extremamente errante e confuso de se prever. Parmoor já havia dado certeza a Briand, delegado francês, de que se esforçava a favor do Brasil, que certamente votaria a favor da manutenção do status quo, mas, na verdade, no momento da eleição, descobrimos mais esta surpresa: a Inglaterra estava para votar no Chile, e não no Brasil! Foi apenas devido a essa inédita ação conjunta latino-americana que Parmoor finalmente acabou se convencendo de votar no Brasil.

Assim que Chile e Cuba se mostraram a favor do Brasil, a Inglaterra não pode deixar de votar em nós. Eis o resultado de como tudo teria sido se houvesse uma diplomacia latino-americana eficaz e contundente cheia de um mesmo propósito desde o início. Os planos de Edwards, com as maquinações secretas de Aguero e as hostilidades paraguaias na Comissão de Transportes e na de Energia; toda a intrincada rede de rivalidades em busca de instrumentalizar a Sociedade das Nações a fim de satisfazer desejos regionais fragmentados estava perto de minar definitivamente todo o prestígio brasileiro na Liga em 1924. Tudo, porém, mudou após a reunião no gabinete do Chile. A

\footnotetext{
${ }^{36}$ Op. cit., p.8.

${ }^{37}$ Op. cit., p.9.

${ }^{38}$ Op.cit., p.10.
} 


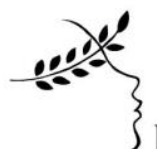

força do "voto conjunto" ficou clara na própria fala de Parmoor. A união da diplomacia americana oferece-nos, assim, um bom aprendizado sobre a sinergia da diplomacia regional e internacional dentro da primeira organização internacional para paz. Essa união latino-americana foi frutífera, porém extremamente fugaz. Passado o período de aliança estratégica e conveniente, a solidariedade diplomática do "voto único" se desfez, e um novo lance de jogos furtivos, de cartas confidenciais e documentos ultrassecretos reaparecerão entre os países vizinhos.

O desenlace entre os latinos será ainda maior em 1925 e 1926, os dois últimos anos do Brasil na Liga. A Inglaterra deixou de apoiar qualquer pretensão brasileira, e o Brasil vetou a entrada da Alemanha no Conselho, causando o que ficou conhecido como crise diplomática. Vamos, então, analisar os dois últimos anos da presença brasileira na Sociedade das Nações, em busca de esclarecer e revelar as causas dessa crise.

\section{Considerações finais}

Muito se tem ainda a descobrir sobre a diplomacia latino-americana na Liga das Nações e seu papel na conformação da política brasileira de segurança de 1920, na qual se inclui a política externa de Arthur Bernardes, questão que concluiremos melhor em nossa dissertação de mestrado. Fica, porém, muito claro o jogo secreto de apoios simulados que Cuba, Chile, Venezuela e Uruguai desenvolveram como forma de apaziguar os pedidos de apoio brasileiros, trabalhando secretamente, contra todas as propostas do Brasil. Ficou claro, porém, ao Brasil, que esses planos furtivos estavam sendo tramados graças ao apoio do Salvador e da França. A imediata reação brasileira foi de reorganizar seu quadro de diplomatas e também agir secretamente com seus aliados, principalmente a França. O estudo da diplomacia latino-americana é fundamental para revelar-nos como as tensões da geopolítica regional levaram a estratégia brasileira à busca pelo lugar permanente no Conselho da Sociedade das Nações. Ficou claro, que entre 1922 e 1925, no único momento em que a diplomacia latino-americana trabalhou realmente de forma conjunta, a posição das Grandes Potências foi enfraquecida. Nessa temporária 


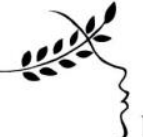

$\begin{array}{lll}\text { FACES DE CLIO } & \begin{array}{l}\text { REVISTA DISCENTE DO PROGRAMA DE } \\ \text { PÓS-GRADUAÇ̃o EM HISTORIA- LFFF }\end{array} & \text { ISSN } \\ 2359-4489\end{array}$

união, o Brasil ganhou vantagens comparativas, demonstrando as potencialidades da verdadeira solidariedade regional. A intrincada rede de interesses geopolíticos de nossa região, porém, não apenas impediu uma posição afirmativa dos mais fracos em relação ao mais fortes como também minou todo o esforço brasileiro em sua candidatura a membro permanente no Conselho. Destarte, devemos considerar as tensões diplomáticas regionais na conformação da política externa brasileira em busca do lugar permanente na Liga das Nações.

\section{Referência bibliográficas}

GARCIA, Eugênico Vargas. Revista Brasileira de História. A diplomacia dos armamentos em Santiago: o Brasil e a Conferência Pan-americana de 1923. São Paulo, v. $23, n^{\circ} 46$, pp. 173-200-2003.

GARCIA, Eugênio Vargas. (2000), O Brasil e a Liga das Nações (1919-1926). Porto Alegre, Editora da UFRGS.

HERZ, Mônica; HOFFMANN, Andréa Ribeiro. Organizações Internacionais. São Paulo:Elsevier, 2004.

HOBSBAWN, Eric. A era dos extremos: o breve século XX. 1941-1991. São Paulo: Companhia das Letras, 1995

LORENZO, Helena Carvalho de. A década de 1920 e as origens do Brasil moderno. São Paulo: UNESP, 1997.

SARAIVA, José Flávio Sombra. História das Relações Internacionais Contemporâneas . São Paulo: Saraiva, 2006. 